DOI: $10.19195 / 2084-5065.49 .4$

\title{
Document examinations in Malta ${ }^{*}$
}

\author{
TREVOR CALAFATO \\ ORCID: 0000-0002-1750-5369 \\ Department of Criminology \\ University of Malta, Malta
}

\section{The context}

Document fraud is intrinsically associated with various criminal activities which include human trafficking, smuggling of migrants and also with the threat of terrorism. Yet, the forensic examination of documents encompasses various aspects that trail back from the production of the document, to the eventual handwriting and signatures found on the document. In addition, the documents under examination vary from a simple piece of paper with some annotations on it, to official documents, such as passports. These wide spectra can already provide an idea that the knowledge, experience and expertise of a document examiner's needs shall be various and in some cases focus on particular aspects.

Additionally, there are experts who do not look at the characteristics that make up the document but would mainly observe particular traits within the handwriting. However, a handwriting expert would only study the handwriting per se and would not consider other aspects that determine the veracity or modifications found on a document. One of the main

I would like to thank those forensic document analysts who willingly provided their feedback on the subject and provided their viewpoints on the under-researched field in Malta. Furthermore, I would like to thank my colleague, Mr John Charles Ellul, for giving unconditional guidance on a subject, which is so close to heart. 
issues of this particular forensic field is that the qualifications that sustain the expertise of these experts are not always transparent and verifiable, since there are no courses at official institutions like a university or other educational entities. Thus, the courts of law of Malta often rely on renowned experts without looking at his or her qualifications. In writing this paper some of the main experts on document analysis were contacted and answered a series of questions to discuss the situation in Malta and how their expertise is employed within the criminal justice system.

Though a rather small island, Malta is not immune from document fraud. A common outcry among the three document analysts encountered was that "the kind of crimes related to forgeries in Malta are common to forgeries being encountered in other parts of the world". Maltese authorities catch individuals with both counterfeit and falsified documents. Though 'counterfeit', 'false', 'falsified' and 'forged' might be considered as very much alike, these terms are not the same particularly in the field of document fraud. Those documents considered as either 'counterfeit' or 'false' are complete copies. This means that in 'counterfeit' or 'false' documents there is nothing original or authentic. As for 'forged' or 'falsified' documents, these are genuine documents that have been altered in some way or form. As indicated by Europol, "forging documents and trafficking in the forgeries are sometimes pursued as ends in themselves, for profit. But these crimes are often means to other ends, such as terrorism, the smuggling of migrants and trafficking in people". ${ }^{1}$

Targeting those offences related to documents is particularly challenging, and the Schengen regulations do not ease this task. A clearer picture of the common use of false documents was discovered when Malta suspended Schengen for a number of days during the Commonwealth Heads of Government Meeting in 2015 and the European presidency in 2017. During these days a number of persons were caught using false documents to enter or exit Malta. ${ }^{2}$ According to open sources these documents came from Italy, Bulgaria, Libya, Greece and Poland among other countries. It does not mean that the person carrying the passport would

1 https://www.europol.europa.eu/crime-areas-and-trends/crime-areas/forgery-of-administrative-documents-and-trafficking-therein (accessed: 2.08.2018).

$2 \mathrm{http} / / / \mathrm{www}$. independent.com.mt/articles/2017-03-07/local-news/49-peoplecaught-using-false-documents-since-start-of-2016-6736171305 (accessed: 15.05.2018). 
necessarily be from the same country. As for fake Maltese passports, police in Bangkok seized a large quantity in $2008 .^{3}$

\section{Legislation}

The forgery of documents is a very serious offence under the laws of Malta. The Criminal Code ${ }^{4}$ (Chapter 9 of the Laws of Malta) dedicates a whole title called "Of crimes affecting public trust". This title contains three sub-titles, which look at three main aspects, namely the following: 1) forgeries of papers, stamps and seals, 2) the forgeries of public and private writings and 3 ) the counterfeiting of currency. The salient part of these three sections will be discussed hereunder. This section will also summarise the law by which the courts appoint court experts.

The first sub-title of the title for this kind of offence is called "Of forgery of papers, stamps and seals". Though this section of the law looks to be quite dated, the wording still encapsulates the cases that might be encountered nowadays. Article 167 of this chapter addresses specifically 'forgery of documents'. This section outlines that a punishment from thirteen months up to four years imprisonment could be obtained if a person is caught using a forged document to obtain payments, deliver goods or attain good from banks or public institutions. Similar punishments would apply when forging any documents to enter offices, banks or other institutions. This section also specifies and diversifies punishment for the forged endorsement of genuine schedules, tickets, orders or documents. In such cases the offender would be liable for a term of imprisonment from nine months to three years (art. 167(3)).

The list of offences related to forgery delves into the forgery of: government debentures and documents by public officers (art. 169); the use of the forged debentures and documents (art. 169); the forgery of government, judicial and official acts, the use of forged acts, judgment, decrees or orders and the use of such forged acts by public officers

3 https:/www.timesofmalta.com/articles/view/20080429/local/fake-maltese-passports-seized-in-bangkok.206047 (accessed: 15.05.2018).

4 Available online: http://justiceservices.gov.mt/DownloadDocument.aspx?app=lom \&itemid=8574\&l=1 (accessed: 5.04.2018). 
(art. 170). This chapter also outlines offences and punishments related to the use, possession and purchasing of counterfeit public seals, stamps and other government marks (art. 171-178). It is important to note the emphasis on the punishment of public officers as this is considered as a more serious crime and in all crimes of forgery where public officers are involved, the punishment would include a perpetual general interdiction (art. 190). The subsequent sub-title of the Criminal Code, called "Of forgery or other public and private writings" commences by delineating the forgery of acts and fraudulent alteration of acts by public officers (art. 179-183). The punishment for all these offences ranges from eighteen months to four years' imprisonment. This sub-title also looks at the malicious use of false documents, declarations, certificates and private writings (art. 184-188).

The third sub-title of crimes affecting public trust delves into the counterfeiting of currency. This is one of the latest additions to this subtitle and dates back only to 2016. This part of the law includes aspects that reflect the contemporary and daily struggle with counterfeiting currencies. This section delves into those crimes that are related to the fraudulent making, alterations and forgeries of coins and banknotes. Liability for such an offence can amount to nine years of imprisonment. Meanwhile the manufacturing of any currency can be punished with a prison sentence ranging from two to ten years (art. 188A-B). The transportation and possession of forged currency can amount to a sentence of five years' imprisonment (art. 188C).

Another section under this sub-title looks at the making, receiving, obtaining or having in possession paper or implements for forgery (art. 188D). This part of the law specifies that the kind of paper would be intended to resemble the special kind of paper used in the making of currency notes. Article 188D also details the possession of frames, moulds or instruments that could be used in the making of such special paper, or also for producing in or on such paper any words, figures, letters, marks, lines, or devices, peculiar to and used in or on any such paper. This section of the law reflects so much of the current situation that also includes the electronic or digital storage of letters, figures and other devices used in the production of counterfeit currencies. Additionally, art. $188 \mathrm{D}(\mathrm{e})$ 
addresses the possession of any paper or similar material which contains holograms or other security features that usually are aimed to act as a protection against counterfeiting.

Another aspect of the Maltese laws looks at how court experts are appointed. When the court necessitates to analyse specific aspects of a case, the court has the power to appoint experts who are knowledgeable and proficient in a specific field, in this case the forensic analysis of documents. The appointment of an expert is also covered in the Criminal Code. Chapter 9 of the Laws of Malta explains that experts will receive the documents and are to witness under oath and to deliver their depositions in writing. All the documents and any other material will be preserved and produced at the trial together with the procès-verbal. As per Chapter 9, art. 561 and 564, the expert shall provide the necessary observations based on the experiments conducted and this shall be confirmed on oath before the inquiring magistrate. Thus, the law provides general rules that empower the court to employ experts from various fields and coming from different entities and backgrounds, and this is no different for experts on forensic document analysis.

The current system entails that the courts of justice can choose an expert witness as its own prerogative. So the expert's allegiance is towards the Court. As a common practice the expert enjoys affability, is trusted and is competent for the task being assigned. There are only a handful of document experts, and they are all well-known within the Maltese criminal justice system. The interviewed experts explained that although there are privately-employed experts that serve the court as document analysts, they all emanate from previous employments within the Malta Police Force.

The Malta Police Force trains personnel on analysing documents mainly in the Immigration Section and the Forensic Science Laboratory. All these individuals have years of experience and are qualified for the job. Thus, the court calls the police and/or some other individual experts to assist on cases where there are suspicions of falsified or forged documents or currencies as well as signatures. To analyse falsified signatures, the court appoints a handwriting or calligraphy expert. The number of handwriting experts is even fewer than that of document experts, and this drastically limits the resources available to the courts. 


\section{Training and qualifications}

The only official entity that deals with such a kind of analysis is the Forensic Science Laboratory ${ }^{5}$ (FSL) within the Malta Police Force. The FSL dedicated a section on document analysis in 2002. This section, called the National Document and Examination Unit, was created to address the alarming needs of analysing documents from the rise of people migrating from Northern Africa and the Far East to carrying falsified travel documents. This unit, which is manned by document experts, provides examination on questioned identity documents as well as travel documents.

Personnel from the FSL and other sections from the Malta Police Force are trained by Frontex. Among the various courses provided by Frontex there is one dedicated to countering document fraud. This is quite an important subject for Frontex (2018, p. 17) particularly when "in 2017, Member States reported around 6,700 persons fraudulently using documents at the external borders, the lowest number since 2012 [...] [but] the number of document fraud detections within the EU/Schengen area increased by almost $9 \%$ and reached its second-highest number since 2013". 6 In the risk analysis report for 2018, Frontex also reports that 138 nationalities were caught using fraudulent documents of which the most common were Moroccans, Ukrainians, Iranians, Albanians, Russians and Turks. ${ }^{7}$

The most common fraudulent documents encountered in Malta are nothing different from the trends found in other European borders. The documents commonly tempered with or counterfeited are the following: passports, identity cards, residence permits and driving licences. Some of the typical alterations include modifications in details, photo substitution, bio-data page substitution, counterfeiting of visas, altered details on visas and also false stamps. This list is very much similar to that issued

5 https://pulizija.gov.mt/en/police-force/police-sections/Pages/Forensic-Science-Laboratory-(FSL).aspx (accessed: 5.04.2018).

6 Frontex, Risk Analysis for 2018, https://frontex.europa.eu/assets/Publications/Risk Analysis/Risk_Analysis/Risk_Analysis_for_2018.pdf (accessed: 5.04.2018).

7 Ibid., p. 22. 
by Frontex where it was described that the fraudulent documents tend to be mainly passports, visas, ID cards, residence permits and also stamps. ${ }^{8}$

During the interviews, the document experts explained that some of the security features of documents can only be identified by the police agencies or other relevant authorities. Documentation about security features of any travel or identity documents are restricted and cannot be disseminated to any other agencies other than the police and embassies where the actual checks can be carried out. Thus, experts who are not police officers, lack such information and moreover specimens to conduct their comparisons. Moreover, such information is not automatically provided to Frontex but everything depends on the contribution of law enforcement officers participating in related workshops.

Personal communications with the document experts revealed that though there are various entities that might provide training on the forensic analysis of documents there are no formal qualifications that could be ensued other than that provided by Frontex. These experts also explained that in order to provide a reliable forensic analysis of fraudulent documents, one would need to have specialised machines which tend to be rather expensive. Upon a thorough analysis of the suspicious document, the gathered evidence is then submitted to the Magistrate, together with a detailed report on the findings. Upon presenting the report the expert is also to give evidence viva voce. The experts are allowed to provide opinions derived from the factual analysis. The evidence and testimony of the expert will be scrutinised and could be challenged by both the defence council and also by the prosecution.

In communicating with these experts it was emphasised that the scientific analysis of a document leads to the same results by whoever analyses the fraudulent document. Thus, even if there are queries in court, this should be easily dealt with. However, the main concern of these experts were the qualifications of some of the court experts. They explained that "experts are subject to be challenged in court on their qualifications, experience and level of expertise. Regretfully for the appointment of experts, there is no formal control". With the aim of creating more controls on who could be potentially recognised and eventually appointed

8 Ibid., p. 49. 
as court experts, the interviewed document analysts stressed that there are no identified controls on who the court is to appoint as an expert, since no proficiency testing is carried out prior to the appointment of an expert. Also, the respondents stressed that the Maltese judiciary are not knowledgeable of what is required to be a document analysis expert. Thus, concertedly the interviewees emphasised that an expert should be appointed only after proving or certifying one's own skills on the subject to a recognised body.

\section{Document examination: Methodology}

The forensic methodology employed in analysing documents requires the employment of scientific applications. Such methodology requires equipment that enables the identification of significant individualised characteristics that distinguishes between questioned and known documents. Forensic document examination entails the use of apposite lighting, magnification and the explanation of the methodology. ${ }^{9}$ These different methodologies are aimed at confirming the authenticity of documents. As Allen clearly explains, this kind of analysis "involves the examination of the materials from which documents are composed, typically inks (which come to be on a document via handwritten entries, typescript and computer printers and conventional printing), toners and paper (and occasionally other materials such as adhesives". ${ }^{10}$

The use of spectroscopic analysis is one of the main methodologies by Maltese forensic document experts. As Allen explicates "comparing inks by their response to visible, infrared and ultraviolet light is a standard technique in document examination and the results can be recorded using suitable cameras". ${ }^{11}$ Various pieces of equipment could be used to look into the absorption, reflectance, luminescence, fluorescence and incandescence of light while examining documents.

9 J.A. Lewis, Forensic Document Examination: Fundamentals and Current Trends, Academic Press Elsevier, Oxford 2014, p. 57.

10 M. Allen, Foundations of Forensic Document Analysis: Theory and Practice, Wiley Blackwell, Sussex 2016, p. 163.

11 Ibid., p. 171. 
Though traditional printing techniques are still widely used, document analysis experts, police and border guards need to be constantly aware of what features of a printed document can determine a counterfeit and altered document, particularly in cases of currency and passports. The document analysts mentioned a series of characteristics that they look for and these include watermarks, offset printing, rainbow printing, intaglio, laser printing and recognition of facial features. These characteristics create intricate designs that would make a document more secure and aim at preventing the forging of copies. The many aspects to document examination of printed documents, altered documents, recovering information about the production of a document, require broad, scientific training. ${ }^{12}$

Ellen explains that forensic document examination also includes providing evidence on disputed handwritings and signatures. However, this kind of analysis differs drastically from handwriting experts. ${ }^{13}$ As Allen (2016, p. 15) indicates, forensic experts focus on the product, that is the handwriting itself and do not give attention to the factors involved in the process of the creation of the handwriting. Some of these factors entail that the speed, fluency and naturalness that compose the skill of writing are taken in consideration. Handwriting experts aim at understanding the reasons that formulate the way we write and at explaining why we differ from each other in this complex skill of writing. This point of view also attempts to theoretically explain and connect the development of the skill of writing together with what is happening in one's brain (Allen, 2016). Considering that human behaviour is still being examined by psychologists and sociologists, among other social sciences, one can deduce that the outcomes of such experts, though valuable, are not based on hard science and results can vary. On the contrary, examining through spectroscopy or other scientific methodologies will always lead to the same results.

This analysis on expertise on document analysis shows that there is a clear need for an increase in the amount of qualified and recognised expertise on document analysis. This entails that the handwriting varies not

12 Ibid.

13 D. Ellen, Scientific Examination of Documents: Methods and Techniques, 3rd ed., CRC Press, London 2006. 
only in between distinct writers but also in a unique writer, due to various factors, for instance age. Thus, the analysis of handwriting is considered to be quite subjective and tends not to involve any particular equipment. This contrasts with the practices of experts of forensic document analysis, who tend to use different equipment to verify whether a document was forged or falsified. The forensic examination of handwriting is a meticulous process, while the expert requires patience, besides an unbiased approach and an eye for detail. This contrasts considerably with the approach adopted by a forensic document examiner, who can identify the outlier between an original document and a forged or counterfeited one, because of a number of unconfutable tests. Forensic document examiners do not enter into or provide details of the person who modified a signature and there are occasions when this has given rise to a number of disagreements in courtrooms.

\section{Concluding comments}

The need for forensic document experts is considered an integral part of the criminal justice system in Malta. This paper also demarks that Maltese legislation has been looking at identifying and dealing with crimes affecting the public trust from different aspects. Together with forgeries of papers, stamps and seals, and also the forgeries of public and private writings, the Criminal Code of Malta is being constantly updated and in recent years an additional section on the counterfeiting of currency has been included.

In order to detect, deal, process and provide strong evidence to prosecute all the numerous cases involving forged or falsified documents, the system employs forensic document examiners. This paper has identified that the pool of these experts is very limited and their qualifications are sometimes questionable. Similar to other technical experts, when inquiring about a document, forensic document examiners use purely scientific methodologies. These scientific results overcome any cognitive bias and personal opinions that could jeopardise a case and would provide solid circumstantial evidence on the documents under examination, helping the judiciary to be more objective in their decision making. 


\section{References}

Allen M., Foundations of Forensic Document Analysis: Theory and Practice, Wiley Blackwell, Sussex 2016.

Ellen D., Scientific Examination of Documents Methods and Techniques, 3rd ed., CRC Press, London 2006.

Lewis J.A., Forensic Document Examination: Fundamentals and Current Trends, Academic Press Elsevier, Oxford 2014.

\section{Legal sources}

Chapter 9, Criminal Code, Laws of Malta.

\section{Internet sources}

Frontex, Risk Analysis for 2018, https://frontex.europa.eu/assets/Publications/Risk_Analysis/Risk_Analysis/Risk_Analysis_for_2018.pdf (accessed: 5.04.2018).

https://www.europol.europa.eu/crime-areas-and-trends/crime-areas/forgery-of-administrative-documents-and-trafficking-therein (accessed: 2.08.2018).

http://www.independent.com.mt/articles/2017-03-07/local-news/49-people-caughtusing-false-documents-since-start-of-2016-6736171305 (accessed: 15.05.2018).

https://www.timesofmalta.com/articles/view/20080429/local/fake-maltese-passportsseized-in-bangkok.206047 (accessed: 15.05.2018).

http://justiceservices.gov.mt/DownloadDocument.aspx?app=lom\&itemid=8574\&l=1 (accessed: 5.04.2018).

https://pulizija.gov.mt/en/police-force/police-sections/Pages/Forensic-Science-Laboratory-(FSL).aspx (accessed: 5.04.2018).

\section{Summary}

The forensics of documents in Malta is constantly increasing in demand. This need is a reaction to the control of human trafficking and the international threat of terrorism, amongst other crimes in Malta and Europe. Besides the constant updates in the Criminal Code, document fraud analysts are increasingly in demand to ensure a more thorough and scientific analysis of forgeries of documents, stamps, seals and private writings.

Keywords: Malta, Criminal Code, forensic document analysis, forged, counterfeit. 